\title{
Concentração de mercado: uma análise para a oferta de crédito pelo setor bancário brasileiro
}

\author{
Alison Luft" \\ Julcemar Bruno Zilli**
}

\begin{abstract}
Resumo
O presente artigo propõe-se a avaliar o comportamento da concentração de mercado para a oferta de crédito pelo setor bancário brasileiro. Parte-se de 1995, ano em que se consolidou o Plano Real até o ano de 2011. Com base em dados secundários, mensurou-se o índice de concentração de Herfindahl-Hirschman (HHI) e as razões de concentração (CR) para os 4, 8 e 18 maiores bancos do Sistema Financeiro Nacional (SFN). As profundas mudanças que ocorreram no setor na última década, destacando-se as mudanças no foco da atividade bancária, o aumento da participação estrangeira e as fusões e aquisições de grande porte, justificam a presente análise. Os resultados indicaram que a concentração é relativamente baixa, apresentado elevação no grau de concentração para a oferta de crédito nos últimos anos.
\end{abstract}

Palavras-chave: Concentração de mercado. Setor bancário. Crédito.

* Bacharel em Ciências Econômicas pela Universidade de Passo Fundo. E-mail: luft.alison@gmail.com

** Economista, Mestre e Doutor em Economia (ESALQ/USP) e professor do Curso de Ciências Econômicas da Universidade de Passo Fundo. E-mail: jbzilli@upf.br.

http://dx.doi.org/10.5335/rtee.v0i41.3737

Submissão: 09/10/2012. Aceite: 17/05/2013 


\section{Introdução}

A concentração de mercado é tema de grande importância para a análise econômica. Por meio da análise do grau de concentração, pode-se identificar a possibilidade de exercício de poder de mercado e, também, a própria estrutura de mercado presente no setor (concorrência perfeita, concorrência monopolística, oligopólio e monopólio).

O setor bancário passou por profundas mudanças na última década. A estabilidade das taxas de inflação, após o Plano Real, mudou o foco de atuação dos bancos. Argumentam diversas correntes que, com a queda das taxas de inflação, os bancos perderam receitas advindas do floating, sendo que sua atuação passou a enfocar a prestação de serviços específicos e a oferta de crédito. $O$ volume de crédito ofertado ampliou-se quanto à participação de instituições públicas, privadas nacionais e privadas estrangeiras. A reestruturação, por meio de programas governamentais, ocorreu concomitantemente com a ampliação da participação estrangeira.

Ocorreu, também, uma ampla onda de fusões e aquisições no setor, o que provocou mudanças quanto ao grau de concentração presente no mercado. Assim sendo, no presente artigo, propõe-se a avaliar o grau de concentração presente no mercado bancário para a oferta de crédito, partindo-se do ano de 1995 até os dias atuais.

Para tanto, utilizaram-se dados secundários provenientes da base de dados do Plano Contábil das Instituições do Sistema Financeiro Nacional (COSIF), divulgada pelo Banco Central do Brasil ( BACEN). São várias as formas de mensuração do grau de concentração de mercado como, por exemplo, razão de concentração, Herfindahl-Hirschman, entropia, índice de concentração compreensível e índice de Hannah e Kay. Entretanto, para a análise da concentração, foram utilizados os cálculos do índice de Herfindahl-Hirschman (HHI) e as razões de concentração (CR) para os 4, 8 e 18 maiores bancos do Sistema Financeiro Nacional (SFN), por se tratar das medidas mais utilizadas pelos órgãos que regulam a concentração de mercado.

\section{Referencial teórico}

O setor bancário passou por significativas mudanças nas últimas décadas, tanto em sua composição, quanto em sua área de atuação. Tem-se destaque para três âmbitos de mudanças: as no foco da atividade que, com a estabilidade da inflação, obrigou os bancos a reestruturarem-se e promoverem mudanças quanto às principais fontes de receita; 0 aumento da participação estrangeira, que ocorreu por meio de fusões e aquisições no setor, principalmente de bancos em dificuldades como forma de saneamento; e a mudança quanto ao grau de concentração, que se alterou significativamente ao longo dos últimos anos. 


\subsection{Mudanças no foco da atividade bancária}

As mudanças no foco da atividade bancária, nos últimos anos, são notórias. A queda das receitas com a inflação promoveu a reestruturação do setor, que passou a dar maior importância a receitas provenientes de serviços e ao crédito.

Os bancos de grande porte, tradicionalmente, operam com clientes maiores a distâncias maiores e com operações mais transparentes, argumentam Berger et al. (2004). Já bancos menores, "em seus primeiros anos de funcionamento, tendem a emprestar mais para clientes pequenos". (DEYOUNG et al. apud FERREIRA, 2005, p. 21).

A informação é um elemento fundamental para os bancos, visto que se depara com a questão da seleção adversa, ou seja, conforme varia a taxa de juros dos empréstimos, os bancos podem se deparar com o ingresso de investidores mais propensos ao risco, aumentando o próprio risco da inadimplência (ERCOLIN, 2009).

De acordo com Ercolin "em um ambiente onde as informações sobre os tomadores são de difícil acesso, pode-se gerar um processo conhecido como seleção adversa, tendo como consequência um cenário de crédito racionado" e como forma de "prevenção, poderiam elevar a taxa de juros, porém atrairiam também a gama de clientes propensos ao risco, elevando assim o risco do portfólio" (2009, p. 54).

Da mesma forma, Costa cita que "o que se verifica, a partir daí, são situações de equilíbrio com racionamento, onde o mercado funciona com volumes ofertados inferiores ao que se esperaria em situações de informação completa." (2004, p. 102). $\mathrm{O}$ alto risco decorrente de uma operação de crédito pode levar o banco a alocar recursos em outras aplicações com lucratividade semelhante. A estabilidade das taxas de inflação promoveu queda nas receitas inflacionárias do floating.

Destacam Paula e Marques que, em um cenário de alta inflação, os bancos obtinham significativa parcela de lucro por meio de floating, em que aplicam valores arrecadados de tributos e taxas, além de depósitos, em títulos públicos, remunerados a taxas próximas à correção monetária, tática utilizada principalmente por bancos públicos (2006, p. 14).

A queda das receitas inflacionárias, entretanto, não trouxe alteração considerável na lucratividade dos bancos, pois compensaram tais perdas com a expansão do volume de crédito e com a cobrança de tarifas relativas a serviços bancários. A rentabilidade média (lucro líquido/patrimônio líquido), por outro lado, não teve redução significativa (MOLINA, 2004).

As receitas obtidas pela inflação, portanto, não mais se verificam. Em contrapartida, a prestação de serviços específicos, mediante a cobrança de tarifas e comissões, e a oferta de crédito ganharam impulso na última década. A oferta de crédito ampliou-se em todos os segmentos, sendo as categorias banco público e privado nacional as mais significativas. 


\subsection{Oferta de crédito}

O crédito pode ser entendido como um recurso destinado ao financiamento de agentes deficitários na economia, tendo um juro atrelado como contrapartida pelo seu uso. Conforme ressalta Clemente e Kühl (2011), o crédito surge da necessidade de transferir recursos de agentes superavitários para agentes deficitários, por meio de instituições financeiras intermediárias. Tem-se, portanto, esta como uma variável de interesse no presente estudo. Há diversas modalidades de crédito conforme a destinação do recurso.

Há basicamente dois tipos de crédito: o direcionado e o livre. O primeiro tem destino específico conforme a legislação e as normas do BACEN, em setores específicos, cujo volume varia de acordo com o percentual sobre depósitos em conta corrente e de caderneta de poupança. Já os créditos livres não têm restrições quanto ao destino, cabendo ao banco o seu direcionamento. Há de se ressaltar que, no caso de recursos direcionados, a obrigatoriedade do destino dos recursos faz com que todos os bancos cumpram as especificações, cujas discrepâncias, portanto, são observadas devido às mudanças no âmbito da captação (GONÇALVES, 2007).

Mais comumente, linhas específicas de crédito distinguem-se entre as categorias pessoa física e jurídica conforme o uso do recurso pelo agente. Para pessoa jurídica, têm-se, normalmente, as seguintes categorias: capital de giro, conta garantida, aquisição de bens, vendor, hot money, desconto de duplicatas e desconto de promissórias. Para pessoa física, são as seguintes: cheque especial, crédito pessoal e aquisição de bens (BACEN, 2000).

Segundo Clemente e Kühl (2011), o crédito financia os setores produtivos da economia em curto, médio e longo prazo mediante garantias, como hipotecas e avais. O setor produtivo da economia brasileira, ao contrário de empresas de outros países, como os EUA, que utilizam o mercado de capitais, utiliza-se prioritariamente de recursos provenientes de instituições financeiras.

A economia brasileira, conforme Ercolin (2009), tornou-se dependente do sistema bancário para levantar recursos, tanto para pessoa física como para pessoa jurídica. Com a estabilidade da inflação a níveis baixos, as operações de crédito ampliaram-se significativamente após o Plano Real. Noticia-se, entretanto, uma queda nas operações de crédito imediatamente após o referido plano.

Na Figura 1, observa-se a evolução na oferta de crédito segundo a origem de capital da instituição. Nota-se elevação do volume de crédito em todas as séries expostas no gráfico. De junho de 1995 até junho de 2001, o setor público liderava a oferta de crédito. Esse quadro reverteu-se após o ano 2000, em que se observa que 
o setor privado nacional igualou-se ao setor público e, a partir de junho de 2005, passou a liderar. Em julho de 2009, o setor público ultrapassou novamente o setor privado, permanecendo no topo do ranking até os dias atuais. $\mathrm{O}$ setor privado estrangeiro apresentou, em todo o período observado, tendência de elevação no volume de crédito concedido, sofrendo pequena inflexão em 2008, possível reflexo da crise financeira.

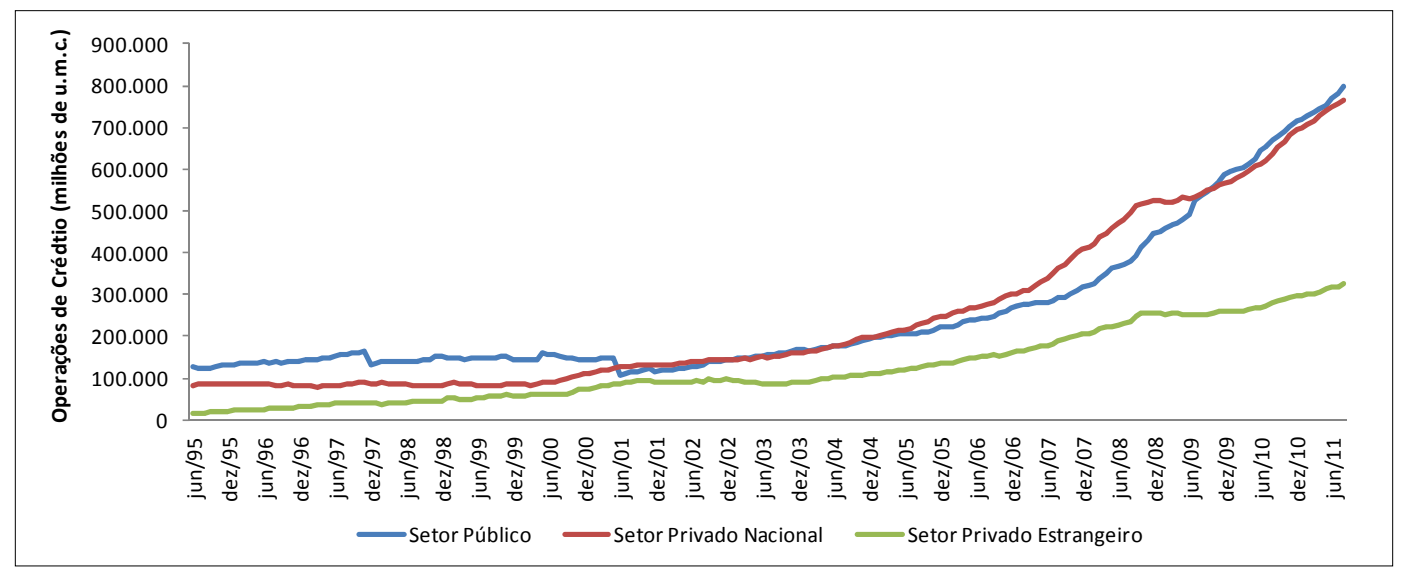

Fonte: Elaboração própria com dados do BACEN (2011).

Figura 1. Operações de crédito totais (milhões de u.m.c), conforme origem de capital, de 1995 até 2011.

A parcela das operações de crédito detida pelo setor privado nacional, em janeiro de 2006, era de 40,94\%, sendo verificado quesua participação nas operações de crédito apresentou sensível aumento, chegando a 44,5\% em agosto de 2008 . A partir daí, o segmento apresenta declínio no percentual detido, registrando 40,6\% em agosto de 2011. O setor privado estrangeiro, em janeiro de 2006, apresentou $22,34 \%$ do total, demonstrando declínio em proporção aos outros, chegando a $21,24 \%$ em agosto de 2008 e 17,21\% em agosto de 2011 .

Já o setor público, inicialmente, em janeiro de 2006, detinha 36,7\% do total das operações de crédito do sistema, reduzindo sua participação em relação aos outros setores, chegando a 34,37\% em agosto de 2008. Posteriormente, observa-se aumento de sua participação, registrando-se 42,18\% em agosto de 2011. Com dados não deflacionados, a variação percentual no volume de crédito ofertado do setor privado nacional, entre janeiro de 2006 e agosto de 2011, apresentou aumento de $256 \%$, a do privado estrangeiro, de $139 \%$, e a do público, também de $256 \%$. Todos os segmentos apresentaram elevação no volume de crédito concedido, ainda que as participações dos setores privado e público nacionais tenham sido proporcionalmente maiores. 


\subsection{Participação estrangeira e reestruturação do setor bancário}

Por meio de programas de incentivo à redução da participação do setor público e de diretrizes governamentais, a reestruturação do setor bancário possibilitou o ingresso de instituições estrangeiras no setor. A entrada maciça de bancos estrangeiros ocorreu após o Plano Real, período em que o número de bancos com controle estrangeiro aumentou significativamente. Ocorreram muitas operações de fusão e aquisição entre instituições domésticas e estrangeiras, resultando na diminuição do número total de bancos no sistema.

Com as crises asiática e russa, na década de 1990, os bancos viram-se em dificuldades. O governo criou, então, o Programa de Estímulo à Reestruturação e Fortalecimento do Sistema Financeiro Nacional (PROER) em 1995, regulamentou o Fundo Garantidor de Créditos (FGC), concedeu poderes ao BACEN para intervir em instituições com problemas de solvência e liquidez, e também implementou as regras do Acordo de Basiléia I. Devido a essas iniciativas governamentais, os bancos estaduais foram os mais atingidos pelas perdas dos ganhos do floating (ARIENTI, 2007).

A reestruturação dos bancos públicos estaduais ocorreu por meio do Programa de Incentivo à Redução do Setor Público Estadual na Atividade Bancária (PROES), que destinava recursos de apoio aos bancos públicos estaduais (CINTRA, 2005).

Para o uso dos recursos provenientes do PROES o banco deveria comprometer-se a liquidar, a privatizar, a transferir seu controle para o governo federal a fim de futura privatização ou transformar-se em agência de desenvolvimento. O objetivo desse programa era não apenas reduzir a participação do estado na economia, mas também resolver o problema do deficit público, muitas vezes financiado pelos próprios bancos estaduais (ARIENTI, 2007).

As instituições públicas federais foram capitalizadas por meio do Programa de Fortalecimento das Instituições Financeiras Federais (PROEF), que procurou regulamentar os bancos federais semelhantemente aos privados, com intuito de fortalecê-los. Ainda que o governo tenha atuado no sentido de evitar a falência de inúmeros bancos, o que possibilitaria uma crise sistêmica, foi inevitável que instituições de grande porte absorvessem outras menores (CINTRA, 2005).

A proliferação de diversos instrumentos financeiros de captação de recursos e cessão de crédito, a ampliação do acesso aos mercados internacionais e as fusões e incorporações decorrentes das condições macroeconômicas estáveis de baixa inflação e do crescimento moderado em países do bloco do euro e dos EUA acabaram por pressionar as instituições desses países a ampliar o volume de negócios, 
expandindo-se para outras nações, fora dos mercados domésticos já saturados (FREITAS, 1999, p. 6). A autora complementa ainda que:

Esse movimento - que se realimenta na própria busca de ampliação da base de clientes e de negócios inerente à dinâmica concorrencial - aponta para uma contínua tendência de diminuição do número de instituições bancárias e de aumento da concentração.

Na segunda metade da década de 1990, dado o conturbado período pós- Plano-Real para o setor bancário no país, com a redução do número de bancos, com o aumento da participação estrangeira no país e com a drástica redução das receitas inflacionarias decorrentes de floating, o setor passou a ser mais concentrado, relata Ercolin (2009, p. 36). O predomínio e a ampliação da participação estrangeira no mercado de crédito no Brasil são significativos, conforme analisa o autor:

A relação crédito/PIB, que estava em $28,1 \%$ em 2005, cresceu para $30,7 \%$ em 2006 , chegando a $34,7 \%$ em 2007 , sendo que, desse total, $43,9 \%$ estava sob o controle dos bancos privados nacionais, $34,1 \%$ das instituições públicas (maioria bancos públicos) e $22 \%$ dos bancos estrangeiros.

A participação estrangeira no mercado bancário brasileiro levou grandes bancos a instituírem filiais no Brasil, com concentração cada vez mais elevada para produtos destinados à pessoa física. Barbachan e Fonseca (2004) destacam que os bancos aumentaram os postos de autoatendimento e realizaram investimentos em tecnologia da informação na segunda metade da década de 1990, como forma de ampliar o acesso aos serviços disponibilizados e conquistar o mercado doméstico. Complementa-se que as perspectivas de retornos elevados devido ao predomínio de competidores locais, relativamente mais fracos, foram os atrativos que se aliaram à necessidade de diversificação fora de mercados domésticos já saturados.

As mudanças de estratégia com relação ao foco no cliente, devido a um aumento do Market share do poder de mercado dos bancos estrangeiros foram expressivas. Os bancos nacionais, para manter sua posição no Market share bancário e evitar que fossem adquiridos por outras instituições, empreenderam um movimento de compra de bancos estrangeiros (CINTRA, 2005, p. 306).

Uma maneira de se mensurar o grau de concentração presente em um mercado é por meio de índice de concentração. Tais índices, na tentativa de resumir o grau de concentração por meio de uma medida, utilizam-se das parcelas de mercado detidas pelas firmas que o integram. Conforme critério pré-estabelecidos, classifica-se o mercado em concentrado ou desconcentrado. 


\subsection{Modelo de concentração}

A chamada "Razão de concentração" capta a participação das "k" maiores firmas do mercado. Considerando-se que há "n" firmas no total, o seu cálculo pode ser verificado na Equação 01.

$$
C R_{k}=\sum_{i=1}^{k}\left(\frac{Q_{k}}{\sum_{i=1}^{n} Q_{i}}\right)
$$

Nela observa-se que $C R_{k}$ representa a razão de concentração das $k$ maiores firmas, $Q_{k}$ representa a parcela de mercado da firma $k$ e $\sum_{i=1} Q_{i}$ mensura a soma da participação de cada firma do mercado. Observa-se que esta "razão" é capaz de mensurar uma fusão/aquisição entre as $k$ firmas consideradas. A disponibilidade de informações e a simplicidade do cálculo tornam essa medida fácil de ser computada. Como bem esclarece Schmidt (2002), há sempre uma variação positiva no valor de $C_{k}$ caso haja um fusão entre firmas, onde uma pertence ao "grupo das $k$ " e outra não; uma variação nula caso a fusão ocorra fora das $k$ firmas consideradas antes e a firma resultante permaneça entre as $(n-k)$ firmas depois da fusão; e uma variação negativa nunca ocorre como resultado de fusão.

Há críticas quanto à capacidade desse índice em medir corretamente a concentração de um mercado. Argumenta-se que as $k$ firmas consideradas em um dado período podem não ser as mesmas em outro período e que se desconsideram as firmas que não fazem parte do "grupo das $k$ " (RESENDE, 1994, p. 26).

Porém, o que se observa na prática, dada a complexidade de um ato de concentração, é a ocorrência de fusões entre grandes grupos industriais, geralmente já inclusos entre as $k$ firmas, além de que o fato de uma firma tomar a posição de outra no ranking dentre as maiores não é tão comum.

Dentre os índices de concentração, destaca-se o HHI, que considera todas as firmas pertencentes ao mercado em questão. $\mathrm{O}$ índice HHI é muito popular na literatura. Abaixo, destaca-se a simplicidade de seu cálculo (Equação 02):

$$
H H I=\sum_{i=1}^{n}\left(\frac{Q_{i}}{\sum_{i=1}^{n} Q_{i}}\right)^{2}
$$


onde $Q_{i}$ é a participação da $i$-ésima firma do mercado e $\sum_{i=1}^{n} Q_{i}$ é a soma da participação de cada firma no mercado.

Nota-se que é atribuído um peso maior às participações maiores, pelo quadrado do valor de cada participação relativa. Esse índice considera, ao contrário do $C R_{k}$, a participação de todas as firmas do mercado e, portanto, uma variação na participação de qualquer uma terá reflexo correspondente no valor do HHI. Os valores extremos do índice são: $1 / n$, em caso de concorrência perfeita, onde cada firma detém a mesma participação; e 1, em caso de monopólio.

Como expõe Resende (1994), uma limitação do índice é que, à medida que varia o total de firmas no mercado, o limite inferior $(1 / n)$ também varia, dificultando comparações, além de que a amplitude de variação também não é constante. Para tanto, Resende (1994) sugere um ajuste que pode ser feito considerando o seguinte:

$$
H H I^{\prime}=\frac{1}{n-1}[n H H I-1] \text { para } \mathrm{n}>1
$$

Dessa forma, os limites passam a ser 1 e 0 , sendo mais próximo de 1 em caso de monopólio e próximo de 0 em caso de concorrência perfeita. Conforme relatam Santos e Santana, "o mercado não será concentrado quando o valor do IHH estiver abaixo de 1.000 e como altamente concentrado quando atingir valor superior a 1.800. Quando se situar no intervalo entre 1.000 e 1.800 , a concentração é considerada baixa (2003, p. 3)." Valores pré-definidos quanto a esse índice devem cuidadosamente ser analisados, pois mercados diferentes têm suas particularidades, além de que a concentração é inerente à própria dinâmica capitalista.

Outro índice de concentração bastante usado na literatura é a entropia de Theil (T). A participação de cada firma é ponderada pelo inverso do logaritmo de $n$. Quando mais próximo de 0 estiver seu valor, mais concentrado é o mercado e, quanto mais próximo de 1 , menor é a concentração. A variável $s_{i}$ representa a parcela de mercado da $i$-ésima firma e $n$ representa o total de firmas no mercado (Equação 04).

$$
T=\frac{1}{\operatorname{Ln}(n)} \sum_{i=1}^{n} s_{i} \operatorname{Ln}\left(1 / s_{i}\right)
$$

O índice de concentração compreensível (CCI) tem a "função de refletir qual a concentração absoluta e relativa da indústria estudada” (BOTELHO, 2006, p. 8). 
Seus limites são 0 e 1, representando maior concentração quando o valor for próximo de 0 , ao passo que um valor próximo de 1 representa desconcentração. A variável $s_{i}$ representa a parcela de mercado da i-ésima firma e "n" representa o total de firmas no mercado (Equação 05).

$$
C C I=s_{i}+\sum_{i=2}^{n} s_{i}^{2}\left[1+\left(1-s_{i}\right)\right]
$$

O índice de Hannah e Kay (HKI) mensura mudanças na concentração devido à entrada ou saída de firmas no mercado (Equação 06). O parâmetro $\alpha$ depende do peso que se queira atribuir às participações mais altas ou mais baixas no mercado. Seus limites são $1 / s_{i}$ e "n". Conforme relata Araújo et al. (2005), o índice assume valor 1 em caso de máxima desigualdade e $n^{(1-\alpha)}$ em caso de participações iguais para cada firma. Os valores de HKI são sensíveis tanto ao valor especificado de " $a$ " como à distribuição dos bancos na indústria. Se “ $a$ ” tende para zero, HKI tende a $N$, e, se " $a$ " tende a infinito, o índice converge ao recíproco da participação do maior banco na indústria.

$$
H K I=\left(\sum_{i=1}^{n} s_{i}^{\alpha}\right)^{\frac{\alpha}{1-\alpha}} \quad \operatorname{com} 0<\alpha \neq 1 .
$$

Há diversos índices, além dos acima mencionados, para analisar a concentração de mercado, porém são suficientes para o presente estudo os índices HHI e as razões de concentração $\left(C_{k}\right)$. De maneira geral, pode-se dizer que todos se propõem a analisar a evolução da concentração de mercado, ainda que esse seja um conceito difícil de avaliar apenas com índices que resumem o mercado. Uma tabela resumo permite comparar os diferentes índices (Tabela 1). 
Tabela 1. Resumo das principais medidas de concentração de mercado.

\begin{tabular}{c|c|c}
\hline Índice & Fórmula de cálculo & Limites de valor \\
\hline $\mathrm{HHI}$ & $H H I=\sum_{i=1}^{n}\left(\frac{Q_{i}}{\sum_{i=1}^{n} Q_{i}}\right)^{2}$ & $1 / \mathrm{n} \leq \mathrm{HHI} \leq 1$ \\
\hline $\mathrm{CR}(\mathrm{k})$ & $C_{k}=\sum_{i=1}^{k}\left(\frac{Q_{k}}{\sum_{i=1}^{n} Q_{i}}\right)^{2}$ & $0 \leq \mathrm{Ck} \leq 1$ \\
\hline $\mathrm{T}$ & $T=\frac{1}{\operatorname{Ln}(n)} \sum_{i=1}^{n} s_{i} \operatorname{Ln}\left(1 / s_{i}\right)$ & $0 \leq \mathrm{T} \leq \mathrm{log}(\mathrm{n})$ \\
\hline $\mathrm{CCl}$ & $C C I=s_{i}+\sum_{i=2}^{n} s_{i}^{2}\left[1+\left(1-s_{i}\right)\right]$ & $0 \leq \mathrm{CCl} \leq 1$ \\
\hline $\mathrm{HKI}$ & $H K I=\left(\sum_{i=1}^{n} s_{i}^{\alpha}\right)^{1-\alpha}$ & $1 / \mathrm{si} \leq \mathrm{HKI} \leq \mathrm{n}$ \\
\hline
\end{tabular}

Fonte: Elaboração própria.

Observa-se que todos os índices utilizam-se das parcelas de mercado de cada firma. Conforme os valores apontados por determinado índice, pode haver indícios de concentração no mercado, sendo que cabe aos órgãos antitrustes a devida avaliação.

\section{Método de pesquisa}

\subsection{Delineamento}

O estudo propõe-se a avaliar o grau de concentração presente no setor bancário brasileiro, partindo-se do ano de 1995 até os dias atuais. Trata-se de um estudo de cunho aplicado, com método dedutivo, técnica descritiva que se utiliza de análise estatística e econométrica para quantificar e identificar relações entre variáveis de pertinência ao tema. 
O método dedutivo parte de premissas que, passíveis de verificação, validam as conclusões (SALMON apud BÊRNI, 2002, p. 92), ressaltando, ainda, que o conteúdo ou informação factual já está contido nas premissas. Ainda que para as ciências sociais esse método é mais restrito, como afirma Gil (2002, p. 33), utiliza-se o método dedutivo aqui em virtude da existência de estudos anteriores e de hipóteses já bem estabelecidas, como é o caso da concentração de mercado que se intensifica com a entrada de bancos estrangeiros mais eficientes. Também torna-se fundamental a utilização do método dedutivo para verificar a própria validade das hipóteses perante a evidência dos resultados.

Com respeito à orientação do estudo, utiliza-se o método quantitativo o qual utiliza uma base de dados com intuito de averiguar a existência de relações entre variáveis que captem em essência o que se pretende descrever. Como afirma Bêrni (2002, p. 29), esse método pode ser utilizado quando já se dispõe de uma teoria ou modelo na literatura que descreva os fenômenos observados.

Hair Jr. et al. caracterizam a abordagem quantitativa como de "mensurações em que números são usados diretamente para representar as propriedades de algo. Como são registrados diretamente com números, os dados estão em uma forma que se presta para a análise estatística" (2005, p.100). Para os autores, a abordagem quantitativa oferece informações resumidas sobre várias características, sendo útil para o mapeamento de tendências.

No que tange ao nível de complexidade, utiliza-se o método descritivo, com o qual, ao abordar algum assunto de interesse a partir de estudos anteriores relativos ao tema em questão, pode-se exaurir boa parte do que já foi investigado e, assim, concentrar o foco do estudo em fenômenos pouco ou superficialmente descritos.

A análise da concentração do mercado para a oferta de crédito utilizou informações provenientes do banco de dados do BACEN. A variável principal foi o total de crédito concedido em cada instituição bancária. Foram utilizados o índice de concentração HHI e as razões de concentração para os 4, 8 e 18 maiores bancos.

\subsection{Variáveis de estudo}

As variáveis utilizadas foram o volume de crédito concedido por instituição financeira e o lucro líquido total do SFN, em dado período. Ao utilizar-se o volume de crédito, optou-se pelo não deflacionamento das séries para fins de análise da concentração, visto que a influência de tal procedimento é pequena em períodos de baixa inflação. Foram utilizados o índice HHI e as razões de concentração $(\mathrm{CR}(\mathrm{k}))$ para as 4, 8 e 18 maiores firmas na tentativa de captar mudanças na concentração do setor em questão.

Teoria e Evidência Econômica - Ano 19, n. 41, p. 150-172, jul./dez. 2013 
a) Operações de crédito concedidas por instituição financeira: corresponde ao volume total de operações de crédito concedido por instituição financeira considerada, classificado sob a rubrica "operações de crédito", conforme conta ${ }^{\circ} 16000001$ do Plano Contábil das Instituições do Sistema Financeiro Nacional (COSIF). Os dados são trimestrais, considerando os meses de março, junho, setembro e dezembro de cada ano, partindo-se de março de 1995 até junho de 2011.

b) Índice de Herfindahl-Hirschman para operações de crédito: é a mensuração do índice HHI para as operações de crédito consideras no item "a". A metodologia empregada não segue o ajuste proposto por Resende (1994), visto que a alteração número de bancos não foi demasiadamente grande para o período em questão.

c) Razão de concentração para operações de crédito: é a utilização da para o volume de crédito das 4, 8 e 18 maiores instituições, consideradas no item "a". Segue a metodologia vista na subseção 2.5.3.

d) Lucro líquido do setor financeiro: é o lucro líquido total do SFN, ou seja, considerando todas as instituições autorizadas a funcionar pelo BACEN, em R $\$$ mil. A possível ocorrência de valores negativos para essa variável corresponde a um prejuízo auferido pelo setor. Da mesma forma que para o item "a", consideramse os meses de março, junho, setembro e dezembro de cada ano, partindo-se de dezembro de 1999 até junho de 2011.

Os dados foram obtidos junto ao BACEN. As operações de crédito são aquelas que constam na rubrica "operações de crédito" do COSIF. O lucro líquido não considera o valor correspondente à despesa com pagamento de juros sobre o capital próprio (JSCP), conforme normas contábeis de publicação de demonstrativos.

O período escolhido para análise da concentração de mercado compreende o período de março de 1995 até junho de 2011. Justifica-se o ano de início para a análise em questão (1995), dado que o Plano Real vigorou a partir de 1994 e trouxe mudanças drásticas no setor financeiro, motivando, portanto, uma análise de longo prazo (15 anos). Para a análise da relação de causalidade, inicia-se por dezembro de 1999 e segue até junho de 2011, conforme a disponibilidade de dados.

\subsection{Procedimentos e técnica de coleta de dados}

Os dados secundários foram obtidos do banco de dados do BACEN, por meio dos balancetes do COSIF. A conta considerada foi a de $\mathrm{n}^{\circ} 16000001$ correspondente a rubrica "operações de crédito" do COSIF, para cada banco considerado. Para o lucro líquido, utilizou-se a base de dados intitulada " 50 maiores bancos e o consolidado do Sistema Financeiro Nacional", também do BACEN. Por meio de planilhas eletrônicas, os dados foram agrupados e deflacionados para fins de análise, conforme os objetivos propostos. Os períodos considerados foram agrupados de forma a tornar a análise mais fiel ao que se pretende inferir. 


\section{Análise dos resultados}

O grau de concentração de mercado no setor bancário brasileiro alterou-se significativamente na última década. As instituições, ao perderem receitas de floating com a estabilidade da inflação, alocaram seus recursos em operações de crédito. As fusões e aquisições alteraram a participação relativa de cada banco no total, além de diminuir o número total de bancos no Sistema Financeiro Nacional. As instituições estrangeiras vêm ganhando participação nesse mercado, tornando-o mais concorrido. As razões de concentração para os 4, 8 e 18 maiores bancos e o índice HHI foram utilizadas para a análise.

As razões de concentração analisam apenas as parcelas detidas pelos $k$ maiores bancos em relação ao total, sendo que suas variações representam mudanças que ocorrem envolvendo as maiores firmas do mercado. Já o HHI incorpora todos os bancos do SFN, sendo permitido analisar, pelo seu valor, o movimento de todo o setor, e não apenas entre as $k$ maiores instituições, como é o caso das razões de concentração. De maneira geral, pode-se dizer que o HHI segue as tendências das razões de concentração, o que é visível na Figura 2.

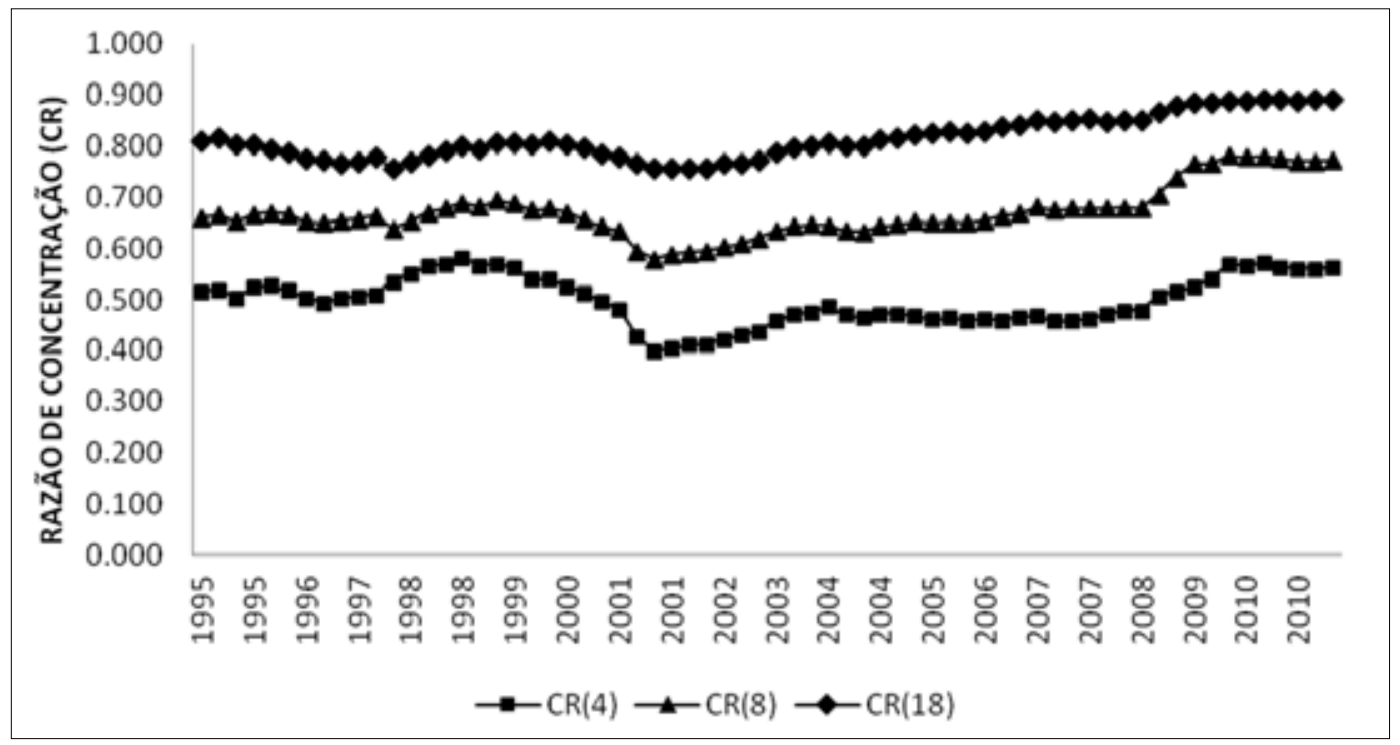

Fonte: elaboração própria com dados do BACEN (2011).

Figura 2. Razão de concentração para os 4,8 e 18 maiores bancos do SFN, para a variável operações de crédito de 1995 até 2011. 
Inicialmente, de março de 1995 até setembro de 1997, observa-se uma leve tendência de queda no CR(18), enquanto que o CR(8) e o CR(4) apresentam-se ascendentes. Para o CR(8), tem-se um valor de 0,639 em dezembro de 1997, chegando a 0,693 em junho de 1999. Para o CR(4), a elevação partiu do valor de 0,510 em setembro de 1997 e alcançou o ponto mais alto de todo o período, em dezembro de 1998 , com um valor de 0,582 . Registra-se um valor de 0,758 no $\mathrm{CR}(18)$, chegando a 0,810 em março de 2000 .

Com relação ao HHI, seu valor é de 0,091 em março de 1995, o qual oscila até setembro de 1997. A partir daí, observa-se um movimento ascendente, que chega a 0,118, o ponto mais alto de todo o período, em junho de 1999. Pode-se afirmar que esse aumento envolveu as parcelas mais altas do mercado e teve grande impacto em todo o setor, pois tanto o $\mathrm{CR}(4)$ quanto o HHI mostram variação significativa (Figura 3).

Esse aumento é fruto dos atos de concentração que ocorreram no período. Ribeiro e Tonin (2011) apresentam as principais fusões e aquisições que ocorreram a partir de 1995. Destaca-se que somente no ano de 1996, ocorreram cinco operações de F\&A. Dentre elas, a compra dos bancos Bamerindus, Nacional e Econômico, bancos de grande porte. Já em 1997 e 1998, ocorreram 10 operações de destaque, figurando o Bradesco e o Santander como compradores, cada um participando em três delas.

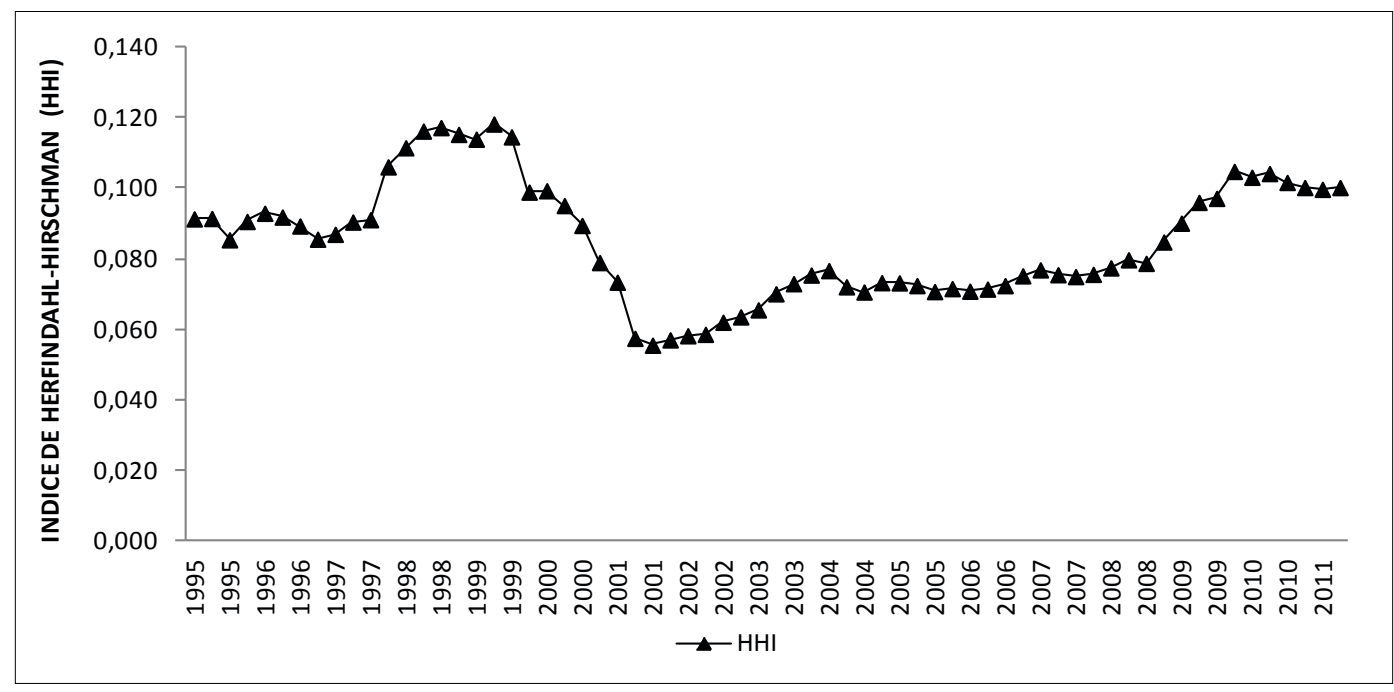

Fonte: elaboração própria com dados do BACEN.

Figura 3. Índice de Herfindahl-Hirschman para o setor bancário, para a variável operação de crédito, de 1995 até 2011. 
Porém, Laureto e Oreiro (2010) argumentam que entre 1997 e 1998, os bancos diminuíram o volume de créditos concedidos, dando preferência a títulos atrelados ao câmbio, como forma de hedge cambial, a títulos públicos e a títulos imobiliários. Anteriormente ao Plano Real, os bancos conviviam com um processo de alta inflação, que inibia a concorrência. Complementa-se que:

[...] da convivência do setor com um processo de inflação crônica e elevada, que inibia o alongamento das operações de crédito bancário ao mesmo tempo em que estimulava as atividades financeiras especulativas, e do crescente desequilíbrio fiscal do Estado [...] (PAULA, 1998, p. 8).

O processo de reajuste, ainda em fase de amadurecimento, possibilitou esse aumento nas razões de concentração, dada as elevações no $\mathrm{CR}(4)$, no $\mathrm{CR}(8)$ e no HHI. O principal fator, pode-se dizer, foram as F\&A do período. Destaca-se, ainda, que, entre 1997 e 1999, o aumento na concentração das operações de crédito deve-se aos resultados do PROES, com a aquisição de bancos públicos por bancos privados (RIBEIRO; TONIN, 2011).

A partir de 1999, o movimento é de declínio em todas as razões, sendo mais acentuado no $\mathrm{CR}(8)$ e no $\mathrm{CR}(4)$. O $\mathrm{CR}(18)$ apresentou um valor de 0,756 em março de 2002. O CR(8) caiu até 0,579 , o menor valor de todo o período, em setembro de 2001, sendo que, para o CR(8), o valor foi de 0,399, também o menor de toda a série.

Medidas governamentais nesse período, destaca Cintra (2006), como o aumento das taxas de juros, dos depósitos compulsórios, o que contraiu a liquidez do setor financeiro, encarecendo o crédito, além do aumento da inadimplência. Os bancos, então, tornaram-se mais seletivos e a concorrência pelo crédito caiu, reduzindo, portanto, o grau de concentração no mercado.

Para o HHI, o movimento também foi de declínio, registrando o ponto mais baixo da série em setembro de 2001, de 0,056. Posteriormente, há uma retomada na concentração, iniciando-se um movimento de ascensão até março de 2004, com um valor de 0,077 .

Silva e Moraes (2011) relatam que o mercado bancário, em 2003, esteve concentrado nas mãos de poucas instituições. Mostra-se que quase a totalidade das operações de crédito estava concentrada em apenas $9 \%$ dos bancos.

Ribeiro e Tonin (2011) destacam que na década de 2000, somente o ITAÚ participou de cinco operações como comprador, e o Bradesco, em mais quatro, também como comprador. É notória a ampliação do market share das maiores instituições, ainda que não se possa afirmar que tal aumento prejudique a concorrência no setor. 
A partir de 2001, a tendência nas três razões é de elevação, até setembro de 2008, quando o $\mathrm{CR}(18)$ apresenta um valor de 0,852 ; o $\mathrm{CR}(8)$, de 0,679 , e o $\mathrm{CR}(4)$, de 0,478. Destaca-se uma elevação abrupta no CR(8), que passa de 0,679 em 2008 para 0,767 em setembro de 2009. A partir dessa data, o CR(8) declina e atinge 0,772 em junho de 2011. O CR(4) também declina, após atingir 0,572 em junho de 2010 , chegando a 0,562 em junho de 2011. Apenas o CR(18) continuou apresentando elevação até 2011, registrando, em junho, 0,893 (Figura 2).

Gonçalves (2007) argumenta que, desde 2003, as instituições financeiras nacionais, objetivando aumento do market share, expandiram as operações de crédito, preferindo rentabilidade ao invés de liquidez, dado o cenário de estabilidade de preços e do câmbio. Em percentual do PIB, as operações de crédito atingiram 30,8\% em janeiro de 2007.

Para avaliar a concentração, Botelho (2006) analisa as curvas de Lorenz para as operações de crédito entre 2003 e 2005 e observa grande assimetria em relação ao que seria uma relação ótima. O autor ressalta, ainda, que há uma tendência de aumento da concentração no mercado de crédito no Brasil.

O aumento da concentração também pode estar relacionado a ganhos de escala. Nesse sentido, Troster (2011) destaca que a instituição bancária pode aumentar e ampliar sua participação devido a economias de grandeza, divididas em três grupos: de escala, associadas ao tamanho da firma; de escopo, da produção conjunta de mais de um produto; e de planta, associadas à produção em mais de uma planta. A existência de economias de grandeza, afirma o autor, implica que bancos maiores são mais rentáveis que bancos menores, havendo tendência de aumentar a participação dos primeiros no mercado.

Para o HHI, segue-se um período de estabilidade no índice até setembro 2008, com um valor de 0,079. O movimento seguinte é abrupto, saltando para 0,105 em dezembro de 2009. A partir daí, o índice apresenta leve declínio até atingir 0,100 em junho de 2011 (Figura 3).

Em relação ao número de instituições, Laureto e Oreiro (2010) relatam que, em 2002, havia 149 bancos no SFN, com 87,58\% dos ativos concentrados entre os 20 maiores. Já em 2009, o número de bancos cai para 137, sendo que 92,05\% dos ativos estavam concentrados nos 20 maiores. Ainda que não seja prudente avaliar apenas o número de bancos no sistema, pode-se observar que essa redução foi significativa e impactante para o setor.

Ao analisar as razões de concentração, observa-se movimentos acentuados nas três razões consideradas, o $\mathrm{CR}(4)$, o $\mathrm{CR}(8)$ e o $\mathrm{CR}(18)$. Sugere-se, portanto, que ocorreram mudanças significativas na parcela do mercado detida pelos maiores 
bancos do SFN. Em geral, as 3 razões de concentração apresentaram comportamento semelhante, sendo que os movimentos mais fortes se deram no CR(8). A média registrada para o $\mathrm{CR}(18)$, durante o período analisado, é de 0,816 ; para o $\mathrm{CR}(8)$, de 0,671; e, para o $\mathrm{CR}(4)$, de 0,498 . O desvio padrão foi de 0,042 para o $\mathrm{CR}(18)$, de 0,050 para o $\mathrm{CR}(8)$ e de 0,048 para o CR(4). A correlação entre os índices é a seguir apresentada.

Observa-se a alta correlação entre o HHI e o CR(4), entre o CR(8) e o CR(18) e entre o $\mathrm{CR}(4)$ e o $\mathrm{CR}(8)$. Sugere-se que a variação na concentração entre os quatro maiores bancos afeta o sistema em grande proporção. Tanto o HHI quanto as razões de concentração são bons parâmetros para avaliar a concentração, cabendo ao pesquisador a escolha do mais apropriado para o que se pretende analisar (Tabela 2).

Tabela 2. Correlação entre as razões de concentração e o índice de Herfindahl-Hirschman.

\begin{tabular}{l|r|r|r|r}
\hline \multicolumn{1}{c|}{ Índice } & \multicolumn{1}{|c|}{$\mathrm{HHI}$} & \multicolumn{1}{c|}{$\mathrm{CR}(4)$} & $\mathrm{CR}(8)$ & \multicolumn{1}{c}{$\mathrm{CR}(18)$} \\
\hline $\mathrm{HHI}$ & 1,000 & 0,972 & 0,656 & 0,281 \\
$\mathrm{CR}(4)$ & 0,972 & 1,000 & 0,753 & 0,400 \\
$\mathrm{CR}(8)$ & 0,656 & 0,753 & 1,000 & 0,870 \\
$\mathrm{CR}(18)$ & 0,281 & 0,400 & 0,870 & 1,000 \\
\hline
\end{tabular}

Fonte: Elaborada pelo autor.

Troster (2011) argumenta que, entre 1994 e 2003, o aumento na concentração, incluindo aí as operações de crédito, deve-se a regulamentações do governo, e são menores que em outros países latino-americanos.

Botelho (2006), por outro lado, complementa que, no Brasil, a parcela representada pelas 50\% menores instituições, detém, em termos de volume de crédito, apenas 3\% do total em 2003. Os maiores bancos, portanto, detém praticamente todo o mercado de crédito no Brasil.

Contrariamente, Paula (1998) afirma que há evidências, de que desde as reformas de 1988, a tendência foi de desconcentração bancária, com a criação de bancos múltiplos e com o aumento no dinamismo dos bancos privados, ampliando sua participação. Pode-se afirmar, portanto, que o mercado de crédito está se tornando mais atrativo e mais concentrado no Brasil. Órgãos antitrustes baseiam-se em critérios pré-definidos para avaliar se a concentração é alta demais.

Nakame e Rocha (2002) citam que os critérios para a concentração ser considerada elevada no setor, conforme determina o Departamento de Justiça (DOJ) norte-americano é, de um HHI acima de 0,18. Para o mercado brasileiro, conforme o Guia para Análise Econômica de Atos de Concentração Horizontal da SEAE/SDE, 
a concentração é elevadaquando o $\mathrm{CR}(4)$ for igual ou superior a $75 \%$ do mercado. Critérios pré-definidos, reitera-se, podem não ser adequados para definir se a concentração é baixa/a elevada em diferentes mercados.

Ribeiro e Tonin (2011) encontram semelhante resultado para o HHI e destacam que o setor, em 2009, é considerado levemente concentrado conforme parâmetros da justiça norte-americana. Ao utilizar o CR(5), observam que aproximadamente $70 \%$ do mercado de crédito é de domínio dos cinco maiores bancos. Pode-se afirmar, conforme os parâmetros acima mencionados, que o mercado de crédito no Brasil não está altamente concentrado, ainda que poucas instituições detenham grande parcela. Ressalta-se que a presente análise considerou as instituições isoladamente e não por conglomerado.

A presença de grandes bancos estrangeiros, as mudanças no foco da atividade e no direcionamento de recursos para o crédito e as transformações estruturais que o setor vem passando, como as inúmeras fusões e aquisições, alterou significativamente o grau de concentração nesse mercado.

A concentração observada, para todo o período analisado, não excede os parâmetros estabelecidos pelos órgãos antitrustes brasileiros no que se considera concentração excessiva. A participação de mercado para as 4 maiores firmas em nenhum momento atingiu $75 \%$ do mercado, sendo o valor limite de 0,18 pontos não atingido também pelo HHI durante o período pbservado. Há autores que argumentam que é necessário um nível elevado de concentração para que haja efetivo exercício de poder de mercado.

\section{Considerações finais}

O estudo buscou avaliar o grau de concentração presente no mercado bancário para a oferta de crédito a partir de 1995 até 2011.

$\mathrm{O}$ setor financeiro brasileiro, historicamente, foi sendo estruturado à medida que surgiram novas necessidades no país. Ainda que os primeiros bancos que surgiram tenriam sido brasileiros, a participação estrangeira verifica-se já no ano de 1863, e, a primeira fusão, em 1853. A regulação no setor fez-se necessária e surgiu conforme o setor foi adquirindo maior complexidade.

Com o advento do Plano Real (1994), o setor bancário passou por profundas mudanças, dado que a estabilidade da inflação a níveis baixos ocasionou a perda de receitas das instituições financeiras. Os ganhos advindos do floating esgotaram-se, obrigando os bancos a considerar mais as receitas provenientes da prestação 
de serviços e da oferta de crédito. O volume de crédito ofertado cresceu e ganhou maior participação no mercado bancário doméstico.

$\mathrm{O}$ aumento da participação estrangeira obrigou o setor a tornar-se mais competitivo. A entrada de bancos estrangeiros ocorreu em grande escala. A reestruturação dos bancos brasileiros ocorreu em meio a uma onda de fusões e aquisições que possibilitaram o aumento na concentração.

Conclui-se que o grau de concentração na oferta de crédito para o setor bancário aumentou desde 1995 até 2011, ainda que se registrem períodos de queda nessa concentração. Até o ano 2000, verificou-se um aumento significativo na concentração, observando-se uma queda subsequente. A partir de 2001, o grau de concentração voltou a crescer e permaneceu em patamar mais elevado até 2011, ainda que este nível não se considere prejudicial ao setor.

Sugere-se que esse aumento tenha sido causado principalmente pelo alto número de fusões e aquisições registrados no setor na última década. A observação que a concentração para os quatro maiores bancos seguiu a tendência do setor reforça a tese de que as mudanças tenham ocorrido no "topo" do mercado. A queda verificada em 2000, pode-se dizer, ocorreu em um momento de redução na oferta de crédito, em que o setor ficou avesso ao risco.

Por fim, cabe ressaltar que o estudo utilizou-se das medidas de concentração mais populares na literatura e que a utilização de outros índices podem trazer resultados mais/menos precisos. 


\title{
Market Concentration: an analysis of credit supply by Brazilian banking sector
}

\begin{abstract}
This paper aims to assess the behavior of market concentration for the provision of credit for the Brazilian banking sector. It starts with 1995, the year in which consolidated the Real Plan until the year 2011. From secondary data measured is the concentration index Herfindahl-Hirschman Index (HHI) and the concentration ratios (CR) for the 4, 8 and 18 largest banks in the financial system. The profound changes that occurred in the industry over the past decade, highlighting the changes in the focus of banking, increased foreign ownership and mergers and acquisitions of large, justifying the present analysis. The results indicated that the concentration is relatively low, and the sector has been showing elevation in the level of concentration for the supply of credit in recent years.
\end{abstract}

Keywords: Market concentration. Banking sector. Credit.

\section{Concentración Del Mercado: un análisis de crédito para la oferta por sector bancario brasileño}

\section{Resumen}

El presente trabajo tiene como objetivo evaluar el comportamiento de la concentración del mercado de la oferta de crédito por parte del sector bancario brasileño. Se inicia con el año de 1995, año en que el Plan Real se consolidó en el año 2011. A partir de datos secundarios medidos es el índice de concentración de herfindahl-hirschman (HHI) y los coeficientes de concentración (CR) para 4, 8 y 18 bancos más grandes del sistema financiero. Los profundos cambios que se han producido en la industria durante la última década, destacando los cambios en el enfoque de la banca, el aumento de la participación extranjera y las fusiones y adquisiciones de empresas grandes, justifican el presente análisis. Los resultados indicaron que la concentración es relativamente baja, por lo que el sector se muestra el aumento en el grado de concentración en la oferta de crédito en los últimos años.

Palabras clave: Concentración del mercado. Sector bancario. Crédito. 


\section{Referências}

ARAÚJO, Luiz Alberto D. et al. Competição e concentração entre os bancos brasileiros. In: Encontro Nacional de Economia, 33, 2005, Rio Grande do Norte. Disponível em: <http://www.anpec. org.br>. Acesso em: 09 abr. 2011.

ARIENTI, Patrícia F. F. Reestruturação e consolidação do sistema bancário privado brasileiro. Ensaios FEE, Porto Alegre, v. 28, n. 2, p. 577-600, out. 2007.

BANCO CENTRAL DO BRASIL (BACEN). Balancetes. Disponível em: <http://www4.bcb.gov.br/ fis/cosif/balancetes.asp >. Acesso em: 22 out. 2011.

. Sistema Gerenciador de Séries Temporais (SGS). Disponível em: <https://www.bcb.gov. br>. Acesso em: 10 set. 2011.

BARBACHAN, José S. F.; FONSECA, Marcelo Maciel. Concentração bancária brasileira: uma análise microeconômica. IBMEC: São Paulo, 2004

BERGER, Allen N. et al. Bank concentration and competition: an evolution in the making. Journal of Money, Credit and Banking, Ohio, v. 36, n. 3, p. 443-451, 2004.Disponível em: <http://www. jstor.org/pss/3838945>. Acesso em: 29 out. 2011.

BÊRNI, Duilio de A. Técnicas de pesquisa em economia. São Paulo: Saraiva, 2002.

BOTELHO, Tiago dos Santos. Concentração bancária no Brasil e em Portugal. 2006. Tese (Mestrado em Finanças e Economia) - Escola de Pós-Graduação em Economia, Fundação Getúlio Vargas, Rio de Janeiro, 2006.

CINTRA, Marcos Antonio M. A reestruturação patrimonial do sistema bancário brasileiro e os ciclos de crédito entre 1995 e 2005. Política Econômica em Foco, nov. 2005 e abr. 2006. Boletim semestral. Disponível em: <http://www.eco.unicamp.br>. Acesso em; 23 out. 2011.

CLEMENTE, Ademir; KÜHL, Marcos Roberto. Intermediação financeira no Brasil: influência da taxa de captação sobre a taxa de aplicação. In: CONGRESSO USP, 6, 2006, São Paulo. Disponível em: <http://www.congressousp.fipecafi.org>. Acesso em: 22 out. 2011.

CORAZZA, Gentil. Crise e reestruturação bancária no Brasil. Banco Central e Sistema Financeiro: crise e supervisão bancária no Brasil. Disponível em: <http://www.ufrgs.br/ppge >. Acesso em: 22 abr. 2011.

COSTA, Ana Carla A. Ensaios em microeconomia bancária. 2004. Tese (Doutorado em Economia) - Faculdade de Economia, Administração e Contabilidade, Universidade de São Paulo, São Paulo, 2004.

ERCOLIN, Tiago M. Evolução da estrutura de mercado bancário e de crédito do Brasil no período de 2001 a 2007. 2009. Dissertação (Mestrado em Ciências) - Escola Superior de Agricultura "Luis de Queiroz" - Universidade de São Paulo, São Paulo, 2009.

FERREIRA, Caio F. Estrutura, concorrência e performance do setor bancário em um mercado heterogêneo. 2005. Tese (Doutorado em Economia) - Faculdade de Economia, Administração e Contabilidade, Universidade de São Paulo, São Paulo, 2005.

FREITAS, Maria Cristina P. A ampliação recente da participação estrangeira no sistema bancário brasileiro. Análise Econômica, Porto Alegre, ano 17, n 32, p. 31-49, set. 1999. Edição Comemorativa 90 anos. 
GIL, A. C. Métodos e técnicas de pesquisa social. São Paulo: Atlas, 1999.

GONÇALVES, Tiago C. O sistema financeiro brasileiro: evolução do crédito no Brasil pós-Plano Real. 2007. Monografia (Graduação em Ciências Econômicas) - Fundação Armando Alvares Penteado, São Paulo, 2007. Disponível em: <http://www.faap.br>. Acesso em: 18 set. 2011.

HAIR Jr., J. F. et al. Fundamentos de métodos de pesquisa em administração. Porto Alegre: Bookman, 2005.

LAURETO, Camilo; OREIRO, José Luis. Rentabilidade e concentração do setor bancário brasileiro no período 2002-2009. In: Encontro Nacional de Economia, 38, 2010, Niterói. Disponível em: <http://www.anpec.org.br>. Acesso em: 2 out. 2011.

MOLINA, Wagner de S. L. A reestruturação do sistema bancário brasileiro nos anos 90: menos concorrência e mais competitividade? INTELLECTUS, São Paulo, n 03, p. 76-95, ago./dez. 2004. Disponível em: <http://www.seufuturonapratica.com.br/intellectus>. Acesso em: 17 set. 2011.

NAKAME, Marcio I.; ROCHA, Bruno. Concentração, concorrência e rentabilidade no setor bancário brasileiro: uma visão atualizada. Disponível em: <http://www.febraban.org.br >. Acesso em: 30 abr. 2011.

PAULA, Luiz Fernando R. Tamanho, dimensão e concentração do sistema bancário no contexto de alta e baixa inflação no Brasil. Nova Economia, Rio de Janeiro, v. 8, n 1, p. 87-116, jul./dez. 1998.

PAULA, Luis Fernando; MARQUES, Maria Beatriz L.Tendências recentes da consolidação bancaria no Brasil. Análise Econômica, Porto Alegre, v. 24, n 45, p. 235-263, mar. 2006.

RÊGO, Elba Cristina L. As regras de prudência bancária do Acordo de Basiléia. Revista do BN$D E S$, Rio de Janeiro, v. 2, n 3, p. 255-266, jun. 1995.

RESENDE, Marcelo. Medidas de concentração industrial: uma resenha. Análise Econômica, Porto Alegre, ano 12, n 21 e 22, p. 24-33, mar./set. 1994.

RIBEIRO, Oscar Felipe R; TONIN, Julyerme Mattheus. Análise da concorrência bancária no Brasil pós Plano Real. In: Encontro de Economia Catarinense, 5, 2011, Florianópolis.Disponível em: <http://www.apec.unesc.ne>. Acesso em: 16 out. 2011.

SANTOS, Marcos Antônio S; SANTANA, Antônio Cordeiro. Concentração e poder de mercado das empresas de artefatos de madeira do Estado do Pará. In: Encontro Nacional de Engenharia de Produção, 23, 2003, Minas Gerais. Disponível em: <http://www.basa.com.br/bancoamazonia2>. Acesso em 17 set. 2011.

SCHMIDT, Cristiane A. J; LIMA, Marcos André. Índices de concentração. Disponível em:<http:// www.seae.fazenda.gov.br/central_documentos>. Acesso em: 29 out. 2011.

SILVA, César Augusto T; MORAES, Marcos C. Concentração do setor financeiro brasileiro após o Plano Real. Congresso USP, 6, 2006, São Paulo. Disponível em:<http://www.congressousp.fipecafi.org>. Acesso em: 3 set. 2011.

TROSTER, Roberto Luis. Concentração bancária. Disponível em: <http://www.febraban.org.br>. Acesso em: 8 maio 2011. 